\title{
Uso do coproduto de etanol de milho na alimentação de aves: Revisão
}

\author{
Use of corn ethanol co-product in poultry feed: Review \\ Uso de subproducto de etanol de maíz en la alimentación de aves: Revisión
}

Recebido: 14/03/2021 | Revisado: 21/03/2021 | Aceito: 25/03/2021 | Publicado: 04/04/2021

\author{
Brena Cristine Rosário Silva \\ ORCID: https://orcid.org/0000-0002-6109-5045 \\ Universidade Federal de Mato Grosso, Brasil \\ E-mail: brenacristine@gmail.com \\ Ana Paula Silva Ton \\ ORCID: https://orcid.org/0000-0002-5826-1874 \\ Universidade Federal de Mato Grosso, Brasil \\ E-mail: anatonn4@hotmail.com \\ Fanny Leonila Velasquez Moreno \\ ORCID: https://orcid.org/0000-0001-6791-8455 \\ Universidade Federal de Mato Grosso, Brasil \\ E-mail: morenovelasquezfanny@gmail.com \\ Leonardo Willian de Freitas \\ ORCID: https://orcid.org/0000-0002-5796-0403 \\ Universidade Federal de Mato Grosso, Brasil \\ E-mail: 1willianf86@gmail.com
}

\begin{abstract}
Resumo
Os gastos com alimentação destacam-se como o fator de maior incidência sobre os custos de produção avícola, e em momentos de aumento do preço de comercialização dos principais insumos como o milho e o farelo de soja, é comum a busca por alimentos alternativos os quais possam propiciar menor custo produtivo e que forneçam adequado aporte de nutrientes. Dentre os alimentos alternativos temos os coprodutos da produção de etanol obtidos a partir de grãos de cerais, os quais apresentam-se como substitutos promissores nas dietas de aves, devido aos altos teores de proteína, aminoácidos, energia e minerais. Em função das diferenças na composição nutricional dos grãos, nos métodos de processamento para obtenção de etanol e de secagem, ocorrem variações na composição nutricional e, consequentemente, na disponibilidade de nutrientes dos coprodutos. Desta forma, diversos estudos têm sido realizados para determinar os valores nutricionais presentes nos diversos coprodutos utilizados na alimentação animal, objetivando formulações de rações cada vez mais precisas. A alta variabilidade, a concentração e a qualidade de nutrientes entre as diferentes fontes de coprodutos, provocam grandes divergências em relação aos níveis de inclusão desses coprodutos recomendados por nutricionistas para dietas de aves. O objetivo desta revisão de literatura é destacar a composição nutricional e o uso de coprodutos de etanol de milho na alimentação de aves, como um alimento alternativo economicamente viável para produção avícola.
\end{abstract}

Palavras-chave: Alimento alternativo; Avicultura; DDGS; HP-DDGS; Nutrientes.

\begin{abstract}
Expenses with food stand out as the factor with the greatest impact of poultry production costs, and in times of increase in the price of commercialization of the main inputs such as corn and soybean meal, it is common to search for alternative foods that can provide lower production costs and provide an adequate supply of nutrients. Among the alternative foods, the co-products of ethanol production obtained from cereals grains, which are promising substitutes in poultry diets, due to high content of crude protein, aminoacids, energy and mineral levels. Differences in the nutritional composition of the grains, and the processing methods for obtaining ethanol and drying may lead to variations in the nutritional composition, and consequently, in the availability of nutrients in the co-products. In this way, several studies have been carried out to determine the nutritional values present in the various co-products used in animal feed, aiming at formulations of increasingly accurate feeds. The high variability, concentration and quality of nutrients between the different sources of co-products, cause great divergences in relation to the levels of inclusion of these co-products recommended by nutritionists for poultry diets. The objective of this literature review is to highlight the nutritional composition and the use of corn ethanol co-products in poultry feed, as an economically viable alternative food for poultry production.
\end{abstract}

Keywords: Alternative food; DDGS; HP-DDGS; Nutrients; Poultry.

\section{Resumen}

Los gastos en alimentación se destacan como el factor con mayor incidencia sobre los costos de producción avícola, y en épocas de incremento en el precio de comercialización de los principales insumos como el maíz y la harina de soja, 
es común la búsqueda de alimentos alternativos, que pueden proporcionar un menor costo de producción y proveer un adecuado aporte de nutrientes. Entre los alimentos alternativos tenemos los coproductos de la producción de etanol obtenidos a partir de granos de cereales, los cuales se presentan como sustitutos prometedores en la dieta de aves, debido a los altos niveles de proteínas, aminoácidos, energía y minerales. En función de las diferencias en la composición nutricional de los granos, en los métodos de procesamiento para la obtención de etanol y el secado, existen variaciones en la composición nutricional y, consecuentemente, en la disponibilidad de nutrientes de los coproductos. De esta forma, se han realizado varios estudios para determinar los valores nutricionales presentes en los diferentes coproductos utilizados en la alimentación animal, apuntando a formulaciones de alimentos cada vez más precisas. La alta variabilidad, concentración y calidad de nutrientes entre las diferentes fuentes de coproductos, provocan grandes divergencias en relación a los niveles de inclusión de estos coproductos recomendados por los nutricionistas para las dietas de aves. El propósito de esta revisión de literatura es resaltar la composición nutricional y el uso de coproductos de etanol de maíz en la alimentación de aves, como un alimento alternativo económicamente viable para la producción avícola.

Palabras clave: Alimento alternativo; Avicultura; DDGS; HP-DDGS; Nutrientes.

\section{Introdução}

Os gastos com a alimentação destacam-se como o fator de maior incidência sobre os custos de produção avícola, podendo representar cerca de $70 \%$ do custo total de produção. As flutuações sazonais nos preços de comercialização de milho e farelo de soja, utilizados, respectivamente, como fonte de energia e proteína para a dieta de aves, são os principais motivos para o encarecimento dos custos com a alimentação (Borah et al., 2019).

É comum a busca por alimentos alternativos que possam reduzir o custo com as rações e que forneçam adequado aporte de nutrientes. Dentre os alimentos alternativos, os coprodutos da produção de etanol, obtidos a partir de grãos de cereais, apresentam-se como substitutos promissores da fração proteica das dietas (Liu, 2011).

Os coprodutos contêm todos os nutrientes do grão que lhe deu origem, de forma concentrada, exceto pela maioria do amido, que é utilizado no processo de fermentação para produção de etanol (Salim et al., 2010). Embora sejam uma fonte rica em proteína bruta, aminoácidos e fósforo, vários fatores podem afetar as características nutricionais e físicas dos coprodutos, causando variabilidade. As principais fontes de variabilidades nutricionais dos coprodutos advêm de diferenças de composição nutricional dos grãos de milho, proporções de solúveis adicionais ao coproduto após a secagem, a eficiência do processo e conversão do amido em etanol, a temperatura e a duração do processo de secagem (Martinez-Amezcua et al., 2007).

Como resultado às variações na composição nutricional dos coprodutos, as porcentagens de inclusão recomendadas podem variar entre 15 a 24\% na dieta de frangos de corte (Min et al., 2015; Shim et al., 2011). Contudo, variações no método de processamento podem melhorar o perfil nutricional dos coprodutos. Algumas indústrias podem extrair óleo do gérmen e remover a fibra dos grãos previamente à fermentação, visando aumentar o rendimento de etanol, enquanto outras indústrias extraem óleo da vinhaça fina (Bregendahl, 2008).

As diferentes técnicas de produção resultam em coprodutos com diferentes características e composições nutricionais. Técnicas que visem o aprimoramento do perfil nutricional dos coprodutos tornam possível o aumento da porcentagem de inclusão desses ingredientes na dieta de aves, sem afetar o desempenho (Jung \& Batal, 2010). Coprodutos com teores de proteína superior a $40 \%$ podem ser produzidos através da remoção de fibras previamente à fermentação. Os grãos secos de destilaria com solúveis com alto teor de proteína, em inglês high protein distillers dried grains with solubles (HP-DDGS), apresentam maior concentração e digestibilidade de energia e aminoácidos, quando comparados ao DDGS convencional (Kim et al., 2008; Jacela et al., 2010).

Para que a indústria avícola possa fazer máximo uso dos coprodutos da indústria de etanol é necessário que sejam realizadas pesquisas para determinar o valor nutricional e a taxa máxima de inclusão de cada coproduto. Diante disso, objetivou-se revisar a literatura sobre coprodutos da produção de etanol de milho na alimentação de aves. 


\section{Metodologia}

Foi realizada uma revisão narrativa (Pereira et al., 2018), através da pesquisa bibliográfica a respeito de coprodutos de etanol de milho na alimentação de frangos de corte, poedeiras comerciais e codornas de postura e cortes. Os artigos e livros utilizados para o preparo desta revisão foram retirados de bases indexadoras como: Scopus, Scielo, Google Scholar e Web of Science. Não foi definido um recorte temporal, pois buscou-se mostrar a evolução acerca do desenvolvimento da utilização de coprodutos de etanol de milho na nutrição de aves.

$\mathrm{Na}$ descrição narrativa são analisadas as produções bibliográficas em determinada área fornecendo o estado da arte sobre um tópico específico, evidenciando novas ideias, métodos ou subtemas que têm recebido maior ou menor ênfase na literatura selecionada (Vosgerau \& Romanowski, 2014).

\section{Resultados e Discussão}

\subsection{Alimentação das aves}

Milho e farelo de soja são os ingredientes mais utilizados na alimentação de aves como fonte de energia e proteína, respectivamente. Estima-se que a cadeia produtiva de aves e suínos seja responsável pelo consumo de 55\% da produção nacional de milho (Abimilho, 2019). De acordo com a Associação Brasileira dos Produtores de Soja - APROSOJA (2019), $48 \%$ do volume de farelo de soja produzido no Brasil é utilizado para produção de rações para animais. Contudo, flutuações sazonais nos preços desses ingredientes podem aumentar os custos com arraçoamentos na avicultura.

A utilização de alimentos alternativos na formulação de rações pode contribuir consideravelmente para redução de custos de alimentação, mantendo-se a eficiência nutricional e produtiva (Gouveia et al., 2020). Todavia, a conveniência da utilização de alimentos alternativos se dá a aqueles a quem possam adquiri-los a preços baixos e próximo de sua propriedade, caso contrário, ocasionará em diminuição nas margens de lucros da atividade (Oliveira et al., 2013).

Atualmente, os coprodutos da produção de etanol têm sido amplamente utilizados como ingredientes para a nutrição animal, visando a substituição de ingredientes de preços mais elevados, como o farelo de soja (Hoffman \& Baker, 2010). De acordo com Cooper e Weber (2012), ruminantes como bovinos de corte e vacas leiteiras, têm sido historicamente os principais consumidores desses alimentos. No entanto, o uso desses coprodutos na alimentação de aves e suínos tem crescido nos últimos anos. Contudo, ainda existem pontos a serem melhorados, do estabelecimento de estratégias alimentares e o emprego de alimentos alternativos de baixo custo e adequado aporte nutricional, para que a produção se torne ainda mais eficiente.

\subsection{Produção de etanol de milho e coprodutos}

Os biocombustíveis surgiram no intuito de mitigar os impactos ambientais e para suprir novas demandas energéticas, diminuindo a importação e produção de combustíveis fósseis (Eckert et al., 2018). O Brasil é pioneiro no uso de biocombustíveis e, atualmente, é o segundo maior produtor de etanol (35.643 milhões de litros), sendo responsável por 30\% da produção mundial de etanol, perdendo apenas para os Estados Unidos (59.809 milhões de litros), responsável por 54\% da produção mundial de etanol (RFA, 2020).

Contudo, a produção de etanol a partir de culturas amiláceas é pouco difundida no Brasil, sendo predominante a obtenção de etanol a partir de cana-de-açúcar. Entretanto, essa realidade é distinta em alguns estados da federação, como no caso de Mato Grosso em que a produção de etanol de milho (1.269.485 mil litros) ultrapassa a produção de etanol de cana-deaçúcar (1.180.190 mil litros) (CONAB, 2020).

O emprego do milho como matéria-prima para a produção de etanol apresenta rendimento industrial de $460 \mathrm{~L}$ de etanol anidro e $380 \mathrm{~kg}$ de DDGS, por tonelada de grãos secos inseridos no sistema (Wyman, 1996).

Segundo Alves et al. (2012), a conversão de grão de cereais a etanol pode ser feita, basicamente, por dois processos: 
moagem úmida ou seca. Muitas vezes há confusão entre nutricionistas e produtores de alimentos quanto às semelhanças e diferenças nutricionais entre os coprodutos da produção de etanol de milho.

Os grãos secos de destilaria com solúveis, em inglês distillers dried grains with solubles (DDGS), são coprodutos obtidos a partir de grãos de cereais, utilizados para produção de etanol pelas indústrias, através do processo de moagem seca. Enquanto, na moagem úmida o grão é embebido e fracionado em componentes primários.

A via úmida era a opção mais comum até os anos de 1990. O processo de moagem úmida (Figura 1) é desenhado para a recuperação e purificação do amido e de diversos coprodutos (gérmen, glúten, fibra e óleo de milho). Desta forma, o amido é separado dos sólidos, hidrolisado por enzimas para liquefação e sacarificação, obtendo-se alta concentração de glicose, que é fermentada para obtenção do etanol (Cinelli et al., 2015).

Figura 1. Fluxograma da produção de etanol através do processo de moagem úmida.

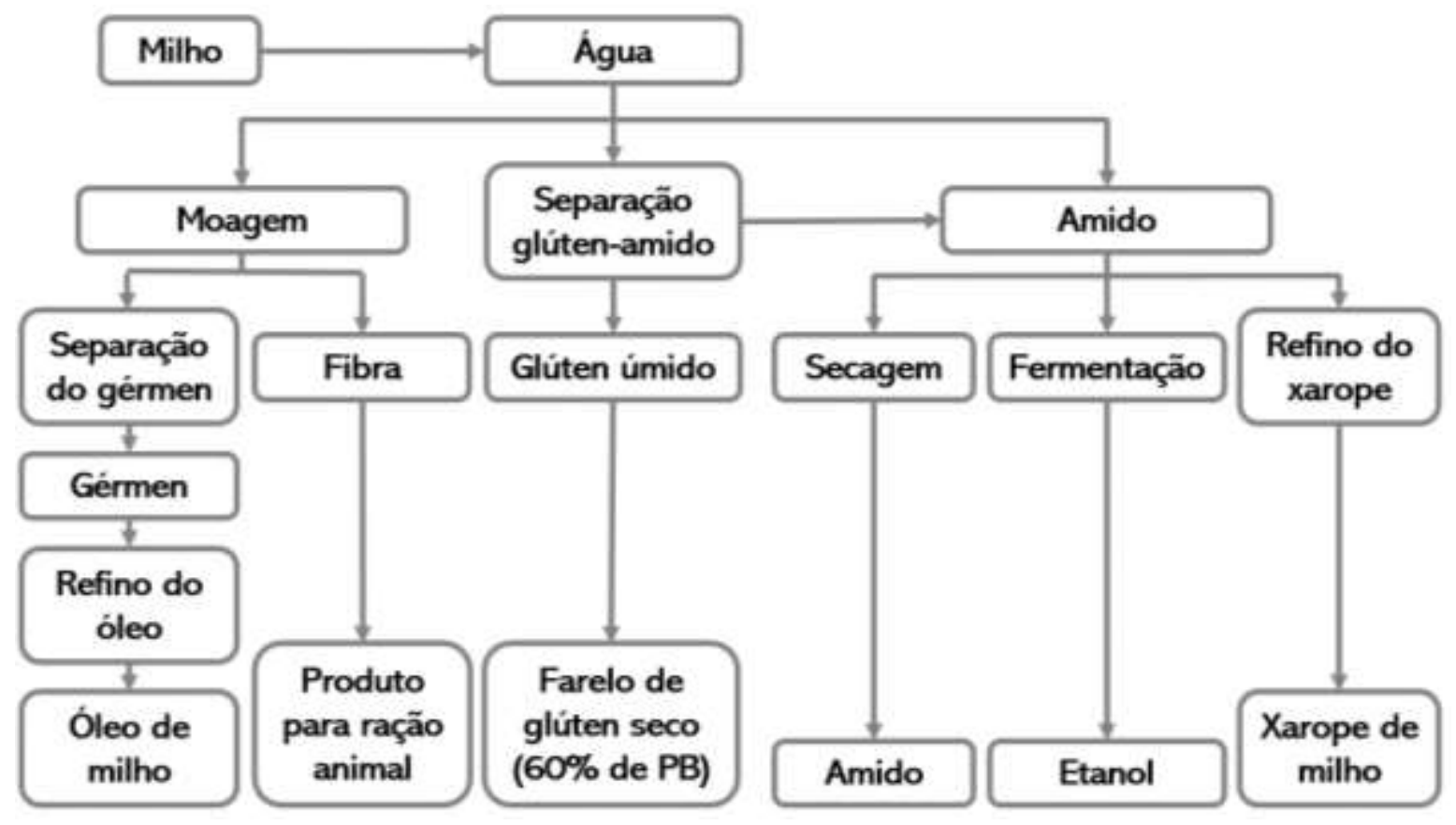

Fonte: Adaptado de RFA (2020).

No processo de moagem úmida, o milho é embebido em solução de dióxido de enxofre por 24 a 32 horas, a uma temperatura de $52{ }^{\circ} \mathrm{C}$. Esse processo aumenta o teor de umidade do grão para cerca de $45 \%$, fazendo com que os grãos amoleçam e inchem, facilitando a separação dos componentes do grão. Transcorrido o tempo, o milho embebido é grosseiramente moído e o gérmen é separado. O objetivo da moagem grossa é partir levemente o grão, para que o gérmen possa ser separado sem danos (Rausch \& Eckhoff, 2016).

Após a separação do gérmen, a pasta de milho degerminado é peneirada para separar o pericarpo do amido e glúten, resultando em uma pasta que é finamente moída, lavada e peneirada. A fibra separada pode ser submetida a processos de lavagem para retirada do amido residual e então seca. Com o gérmen e a fibra separados, a pasta de milho moído é rica em amido e proteínas. O glúten é separado do amido devido sua menor densidade $(1,06 \mathrm{~g} / \mathrm{cm} 3$ para o glúten vs $1,6 \mathrm{~g} / \mathrm{cm} 3$ para o amido), e o amido pode ser fermentado para produção de etanol (Rausch et al., 2019).

No entanto, devido ao menor investimento e maior rendimento da produção de etanol, as indústrias fazem uso do processo de moagem à seco (Figura 2), sendo responsável por mais de 70\% da produção de combustíveis à base de grãos (Kim \& Dale, 2009). Além disso, o processo de moagem à seco permite que as empresas obtenham lucro adicional do coproduto 
não-etanólico produzido, permitindo um portfólio mais amplo de produtos para o mercado (Monceaux \& Kuehner, 2009).

Figura 2. Fluxograma da produção de etanol através do processo de moagem a seco.

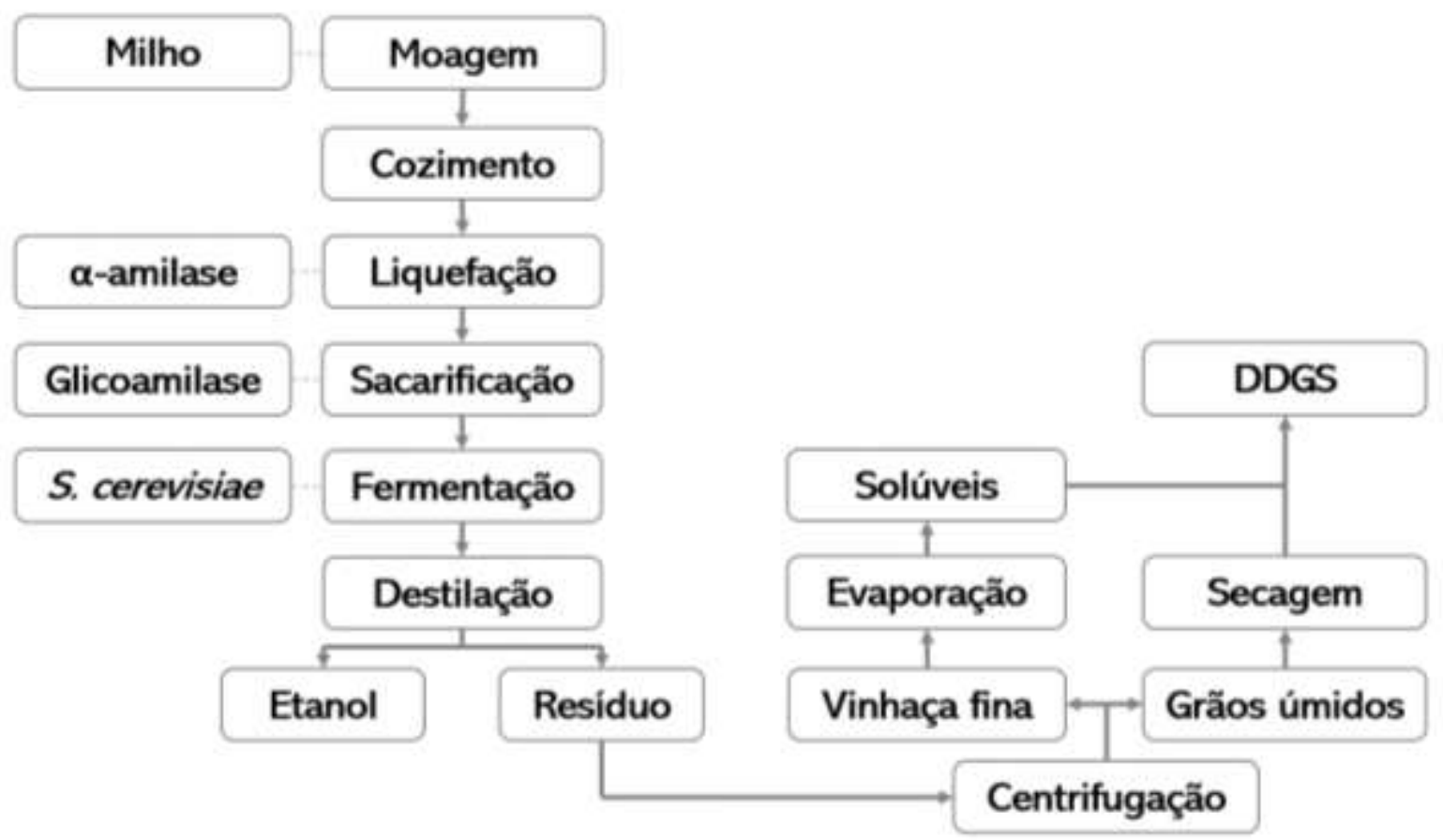

Fonte: Adaptado de El-Hack et al. (2015).

Geralmente a limpeza dos grãos de milho constitui a primeira etapa do processamento da moagem seca, de modo a reduzir a presença de materiais estranhos e contaminantes. Em seguida os grãos são moídos, utilizando-se moinhos tipo martelos. A granulometria normalmente utilizada varia entre 3 a $5 \mathrm{~mm}$ de diâmetro, uma vez que partícula menores maximizam o rendimento de etanol (Kelsall \& Lyons, 1999).

Posteriormente, adiciona-se água e $\alpha$-amilase, para que se forme uma pasta e ocorra a quebra das ligações $\alpha 1,4$ glucosídicas, liberando dextrina, maltose, glicose, tetroses e maltotrioses. Em seguida, é feita a cocção do mosto à 90-105 ${ }^{\circ} \mathrm{C}$, para eliminação de microrganismos, e arrefecimento até aproximadamente $32{ }^{\circ} \mathrm{C}$, para adição da glicoamilase, enzima que converte dextrina em glicose (El-Hack et al., 2015). Em sequência, ocorre a fermentação da glicose em etanol, através do uso de leveduras (Saccharomyces cerevisiae).

Por fim, o etanol é purificado através do processo de destilação e os componentes não fermentáveis como proteínas, lipídeos, fibras, minerais e vitaminas, seguem para um conjunto de centrífugas onde ocorre a separação da fração sólida, que constituem os grãos destilados úmidos, e da fração líquida, que pode ser utilizada para se extrair o óleo ou concentrada em evaporadores, gerando os destilados solúveis condensados (El-Hack et al., 2015).

Várias tecnologias têm sido desenvolvidas para aumentar o valor nutricional do DDGS, gerando novos coprodutos para diversificação do mercado. Dentre elas, o fracionamento do DDGS visando a remoção da fibra por peneiração e aspiração de ar (Srinivasan et al., 2009). Esses processamentos alteram a composição nutricional dos coprodutos, o que pode possibilitar maiores níveis de inclusão na alimentação de não ruminantes, como a tecnologia patenteada FST ${ }^{\text {TM }}$ (Fiber Separation Technology ${ }^{\mathrm{TM}}$; Figura 3), que dá origem a coprodutos com menores teores de fibra dietética total (19,7\%), maiores quantidades de proteína bruta (40\%) e de extrato etéreo (15,0\%) (Kim et al., 2008). 
Figura 3. Fluxograma da produção de etanol através do processo de moagem a seco com utilização da tecnologia Fiber Separation Technology ${ }^{\mathrm{TM}}\left(\mathrm{FST}^{\mathrm{TM}}\right)$.

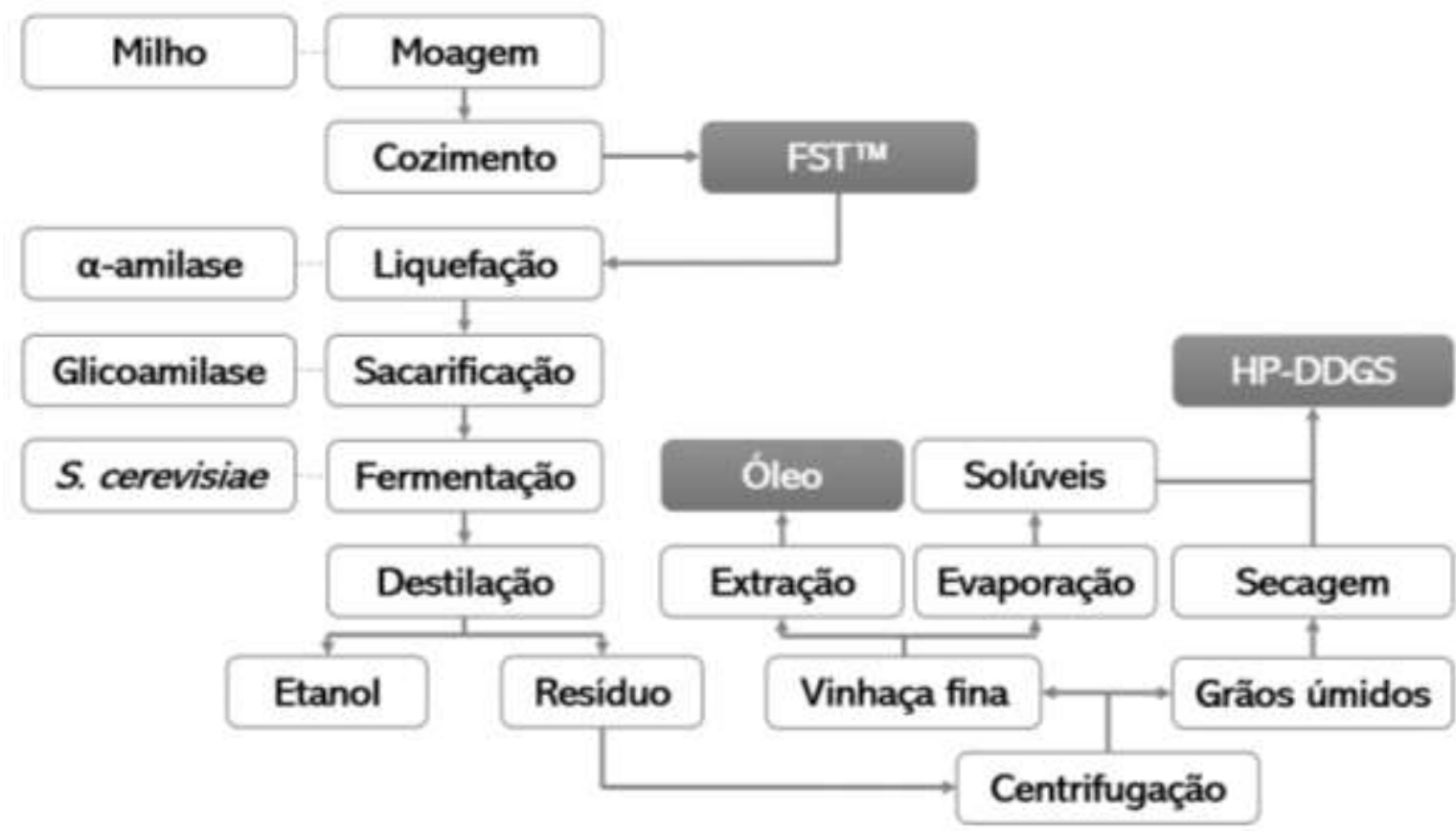

Fonte: Adaptado de El-Hack et al. (2015) e FS Bioenergia.

\subsection{Composição nutricional dos coprodutos de etanol de milho}

As rações formuladas para aves são constituídas basicamente por milho e farelo de soja, que apresentam alta qualidade nutricional, porém são ingredientes de custo elevado. A substituição dos alimentos rotineiros por alternativos é uma opção para redução dos custos, contudo deve-se conhecer a composição química e os coeficientes de metabolizabilidade do ingrediente a ser incluído nas rações (Schone et al., 2017).

Determinar a composição química dos coprodutos de etanol é uma tarefa difícil, visto que seus componentes e valor nutritivo sofrem grandes variações. Fatores como a qualidade da matéria-prima utilizada, processo de obtenção de etanol, eficiência de conversão do amido em etanol, variações nas proporções de mistura dos componentes dos coprodutos, temperatura e duração do processo de secagem, podem influenciar a composição nutricional dos coprodutos (MartinezAmezcua et al., 2007; Shurson \& Alghamdi, 2008; Spiehs et al., 2002).

Desta forma, como as indústrias de etanol fazem uso de diferentes tecnologias de processamento e, também, de diferentes matérias-primas, diversos estudos têm sido realizados para determinar os valores nutricionais presentes nos diversos coprodutos utilizados na alimentação animal (Tabela 1), objetivando formulações de rações cada vez mais precisas. 
Tabela 1. Composição bromatológica e aminograma total de diferentes coprodutos de etanol, com base na matéria seca.

\begin{tabular}{|c|c|c|c|c|}
\hline \multirow{2}{*}{ Item, $\%$} & \multicolumn{2}{|c|}{ DDGS } & \multicolumn{2}{|c|}{ HP-DDGS } \\
\hline & [1] & [2] & [3] & [4] \\
\hline Matéria seca & 86,32 & 86,60 & 83,10 & 91,80 \\
\hline Proteína bruta & 29,82 & 25,40 & 34,10 & 46,80 \\
\hline Extrato etéreo & 10,80 & 11,40 & 7,91 & 3,40 \\
\hline Fibra bruta & ND & 7,04 & 8,35 & 0,51 \\
\hline FDN & 27,97 & ND & ND & ND \\
\hline FDA & 9,38 & ND & ND & ND \\
\hline Cálcio & ND & 0,04 & ND & 0,24 \\
\hline Fósforo total & ND & 1,04 & ND & 0,92 \\
\hline EMA (kcal/kg) & ND & 2.175 & 2.629 & ND \\
\hline \multicolumn{5}{|c|}{ Aminoácidos essenciais totais } \\
\hline Arginina & 1,27 & 1,15 & 1,49 & 2,07 \\
\hline Histidina & 0,63 & 0,74 & 0,88 & 1,28 \\
\hline Isoleucina & 1,54 & 0,95 & 1,26 & 1,80 \\
\hline Leucina & 3,65 & 2,90 & 4,32 & 5,55 \\
\hline Lisina & 0,83 & 0,83 & 1,16 & 1,13 \\
\hline Metionina & 0,50 & 0,42 & 0,74 & 1,05 \\
\hline Fenilalanina & 1,69 & 1,27 & 1,57 & 2,40 \\
\hline Treonina & 1,18 & 1,05 & 1,31 & 1,68 \\
\hline Triptofano & 0,22 & 0,16 & 0,30 & ND \\
\hline Valina & 1,82 & 1,22 & 1,60 & 2,37 \\
\hline \multicolumn{5}{|c|}{ Aminoácidos não essenciais totais } \\
\hline Alanina & 1,67 & 2,46 & ND & 3,39 \\
\hline Ácido aspártico & 1,69 & 2,18 & ND & 3,48 \\
\hline Cisteína & 0,38 & 0,56 & 0,58 & 0,86 \\
\hline Ácido glutâmico & 4,62 & 4,37 & ND & 8,10 \\
\hline Glicina & 1,12 & 1,19 & 1,25 & 1,65 \\
\hline Prolina & 2,14 & 2,12 & ND & ND \\
\hline Serina & 1,30 & 1,24 & 1,60 & 2,37 \\
\hline Tirosina & 0,87 & 1,22 & 1,34 & ND \\
\hline
\end{tabular}

Fonte: [1] - Osho et al. (2019); [2] - Roper et al. (2019); [3] - Fries-Craft \& Bobeck (2019); [4] - Hussain et al. (2019); FDN - fibra insolúvel em detergente neutro; FDA - fibra insolúvel em detergente ácido; EMA - energia metabolizável aparente; ND - não determinado.

A depleção do amido contido nos grãos de milho durante o processo de produção de etanol leva a concentração dos nutrientes não fermentados, fazendo com que os coprodutos apresentem baixas concentrações de amido e altas concentrações de proteínas, lipídeos e minerais (Liu, 2011; Salim et al., 2010). Devido ao alto teor de proteína bruta, os coprodutos são empregados como fonte proteica na nutrição de monogástricos. Contudo, existem grandes variações nos teores de proteína bruta, que se reflete no perfil de aminoácidos, principalmente lisina (0,72 a 1,02\%) e metionina $(0,49$ a $0,69 \%)($ Spiehs et al., 2002). Variações no teor de proteína bruta dos coprodutos podem ocorrer dentro de uma mesma usina, devido às mudanças na 
composição dos cereais, quantidade de solúveis adicionado aos grãos destilados ou ao uso de altas temperatura durante o processo de secagem (Bottger \& Sudeum, 2017).

A digestibilidade verdadeira dos aminoácidos nos coprodutos pode variar substancialmente entre as empresas produtoras de etanol (Batal \& Dale, 2006; Fastinger et al., 2006) e pode, também, variar de lote para lote dentro de uma mesma empresa produtora de etanol. A principal causa de variação é o processo de secagem (Fontaine et al., 2007). O calor pode aumentar a digestibilidade das proteínas, modificando sua estrutura terciária e secundária. No entanto, durante a secagem de grãos destilados, o calor geralmente causa efeitos negativos. O calor induz a reação de Maillard, como resultado, a digestibilidade dos aminoácidos pode ser reduzida por meio de modificações na cadeia amino lateral ou por meio de novas ligações cruzadas, e pode ocorrer também a destruição completa dos aminoácidos (Mauron, 1990).

Em particular, a digestibilidade da lisina varia substancialmente devido à sua susceptibilidade aos danos causados pelo calor durante o processo de secagem (Fontaine et al., 2007; Stein et al., 2006). Na reação do Maillard, o grupo $\varepsilon$-amino da lisina reage com açúcares redutores. Como as aves não possuem enzimas capazes de romper a ligação entre a lisina e o resíduo de açúcar, o produto da reação não é absorvido ou é absorvido e excretado por não estar disponível para a síntese proteica (Bregendahl, 2008).

O emprego de processos de fracionamento pode influenciar a composição e a disponibilidade de aminoácidos. Kim et al. (2008) relataram que a digestibilidade de aminoácidos também varia em função do tipo de coproduto produzido. Coprodutos de alta proteína, como o HP-DDGS, apresentam maiores valores de digestibilidade verdadeira de aminoácidos, quando comparados a DDGS convencional. Contudo, especificamente, a digestibilidade da lisina foi igual nos dois coprodutos avaliados.

De acordo com Batal e Dale (2006) a digestibilidade verdadeira da lisina do DDGS variou de 46 a $78 \%$, para galos cecectomizados. Vale ressaltar que o conteúdo analisado de lisina total pelos autores também variou consideravelmente, entre 0,39 a 0,86\%. Fontaine et al. (2007) sugerem que entre 10 a $40 \%$ da lisina contida no DDGS pode ser danificada pelo calor e, que alguns lotes superaquecidos, podem perder até $59 \%$ do seu conteúdo de lisina.

Altas temperaturas também podem afetar a parede celular dos grãos, promovendo a ligação de compostos nitrogenados à fibra e a formação de polímeros de lignina, ocasionando altos teores de fibra insolúvel em detergente ácido (FDA), lignina e nitrogênio insolúvel em FDA (Kleinschmit et al., 2007). Para monogástricos, o aumento de nitrogênio insolúvel em FDA pode diminuir a digestibilidade ileal do nitrogênio devido à falta de enzimas fibrolíticas (Bottger \& Sudeum, 2017).

A fração fibrosa não é convertida em etanol e, como resultado, os coprodutos contém, aproximadamente, três vezes mais fibra do que o grão de milho. Sendo que, a maior parte da fibra contida nos coprodutos é insolúvel (35\%), e apenas $6 \%$ da fibra é solúvel (Tabela 2; Stein \& Shurson, 2009). Alguns coprodutos, como o HP-DDGS apresentam menor teor de fibra, pois o grão de milho passa por um processo de separação de fibra previamente à fermentação.

De acordo com Foltyn et al. (2013), o alto teor de fibra pode ocasionar variações nos valores de energia metabolizável, embora essa alteração também pode estar relacionada ao percentual de extrato etéreo do coproduto. Schone et al. (2017) avaliaram os valores energéticos de DDGS para frangos de corte aos 21 dias de idade, e relataram valor de energia metabolizável aparente (EMA) e energia metabolizável aparente corrigida pelo balanço de nitrogênio (EMAn) de 2.461 e $2.282 \mathrm{kcal} / \mathrm{kg}$, respectivamente, valores esses semelhantes aos do farelo de soja e inferiores ao do milho. 
Tabela 2. Composição polissacarídica não amilácea de amostras de DDGS de milho, com base na matéria seca.

\begin{tabular}{|c|c|c|c|c|}
\hline \multirow{2}{*}{ Item, $\mathrm{g} / \mathrm{kg}$} & \multicolumn{4}{|c|}{ DDGS de milho } \\
\hline & Mínimo & Máximo & Média & $\mathrm{CV}$ \\
\hline \multicolumn{5}{|l|}{ PNA total } \\
\hline Total & 250,0 & 337,0 & 293,5 & 0,09 \\
\hline Solúvel & 16,0 & 65,0 & 40,5 & 0,47 \\
\hline Celulose & 52,0 & 91,0 & 71,5 & 0,16 \\
\hline \multicolumn{5}{|l|}{ Xilose } \\
\hline Total & 67,0 & 100,0 & 83,5 & 0,10 \\
\hline Solúvel & 1,0 & 16,0 & 8,5 & 0,62 \\
\hline \multicolumn{5}{|l|}{ Arabinose } \\
\hline Total & 56,0 & 72,0 & 64,0 & 0,07 \\
\hline Solúvel & 2,0 & 15,0 & 8,5 & 0,45 \\
\hline \multicolumn{5}{|l|}{ Glicose } \\
\hline Total & 21,0 & 44,0 & 32,5 & 0,13 \\
\hline Solúvel & 0,0 & 16,0 & 8,0 & 1,90 \\
\hline \multicolumn{5}{|l|}{ Manose } \\
\hline Total & 12,0 & 20,0 & 16,0 & 0,11 \\
\hline Solúvel & 4,0 & 9,0 & 6,5 & 0,29 \\
\hline \multicolumn{5}{|l|}{ Ácidos urônicos } \\
\hline Total & 14,0 & 20,0 & 17,0 & 0,08 \\
\hline Solúvel & 3,0 & 6,0 & 4,5 & 0,11 \\
\hline
\end{tabular}

CV - coeficiente de variação. Fonte: Adaptado de Pedersen, Dalsgaard, Bach Knudsen, Yu \& Laerke (2014).

Os valores de EMA do DDGS variam de acordo com a espécie e estado fisiológico, com grande parte da variação relacionada ao teor de fibra dietética. Segundo Cozannet et al. (2010), caso o FDA seja utilizado como preditor do conteúdo de fibra dietética, estima-se que os valores de energia metabolizável podem ser reduzidos em 0,24 MJ (aproximadamente 57,32 kcal) para cada aumento de $1 \%$ do FDA. Em geral, pode-se concluir que o alto conteúdo de fibra dietética do DDGS penaliza seu valor energético, e esses coprodutos devem ser empregados, preferencialmente, em categorias com maior capacidade de aproveitamento dos altos teores de fibra dietética, por exemplo, galos (Noblet et al., 2012).

O grão de milho contém aproximadamente $0,3 \%$ de fósforo total, contudo a maioria do fósforo está na forma de fitato e, portanto, não pode ser utilizado pelas aves. Por outro lado, a concentração de fósforo nos coprodutos pode variar entre 0,59 a 0,95\% (Batal \& Dale, 2006; Martinez-Amezcua et al., 2007; Stein et al., 2006; Spiehs et al., 2002), a maior parte dos quais pode ser digestível.

O processo de fermentação resulta na liberação de uma porção do fósforo ligado ao fitato no milho, o que, por sua vez, resulta em uma maior digestibilidade de fósforo nos coprodutos do que no grão de milho (Stein, 2008). Loy e Lundy (2019) sugerem que durante o processo de fermentação, aparentemente, a levedura empregada fornece fitase em quantidades suficientes para hidrolisar o ácido fítico em fósforo inorgânico disponível.

A grande variação no conteúdo de fósforo pode ser decorrente da variação do teor de fósforo no grão de milho e nos resíduos de amido dos coprodutos. Contudo, a taxa de adição de solúveis é o fator que apresenta maior impacto na concentração de fósforo, uma vez que os solúveis contêm três vezes mais fósforo que os grãos destilados (Martinez-Amezcua 
et al., 2007).

O conteúdo de cálcio, potássio, enxofre e sódio no grão de milho é razoavelmente baixo. Como esperado, o teor de cálcio e potássio nos grãos destilados são três vezes mais altos do que no grão de milho, porém os teores de enxofre e sódio é maior do que o esperado. O teor "extra" de enxofre nos coprodutos advém do ácido sulfúrico (H2SO4) adicionado durante o processo de produção de etanol (Bregendahl, 2008). O ácido sulfúrico é adicionado para ajustar o pH ao nível ótimo nas várias etapas do processo. O teor de enxofre dos coprodutos pode variar entre 0,3 a 1\% (Batal \& Dale, 2006; Spiehs et al., 2002).

Leeson e Summers (2005) sugerem não haver problemas no fornecimento de DDGS com alto teor de enxofre para aves, visto que, frangos de corte toleram níveis de enxofre na dieta de até $0,5 \%$ e poedeiras podem tolerar níveis ainda maiores. Contudo, é importante ressaltar que o enxofre pode interferir na absorção de cálcio e outros mineiras no intestino delgado, e, portanto, pode influenciar na deposição de minerais nos ossos e na casca dos ovos.

Assim como o enxofre, o teor de sódio nos coprodutos é maior do que no grão de milho, e pode variar de 0,09 a 0,52\% (Batal \& Dale, 2006; Spiehs et al., 2002).

A causa do incremento de sódio é desconhecida, mas pode resultar de diferenças na qualidade da água nas usinas de etanol (Bergendahl, 2008). Embora as aves possam tolerar altos níveis de sódio na dieta, é importante monitorar e ajustar esses níveis quando grandes quantidades de DDGS forem fornecidas às aves. Visto que, altos níveis de sódio na dieta ocasionam aumento no consumo de água, o que pode influenciar a qualidade da cama (Klasing \& Austic, 2003).

\subsection{Uso de coprodutos de etanol de milho na alimentação de aves}

A alta variabilidade, a concentração e a qualidade de nutrientes entre diferentes fontes de coprodutos, provocam grandes divergências em relação aos níveis de inclusão desses coprodutos recomendados por nutricionistas para dietas de aves (Abudabos et al., 2017).

Abudabos et al. (2017) avaliaram o efeito da inclusão de DDGS de milho (0, 6, 12, 18 e 24\%) e enzimas (Rovabio® \& Tomoko®) na alimentação de frangos de corte e observaram que dietas contendo a partir de $12 \%$ de DDGS reduziram o ganho de peso e pioraram a conversão alimentar de frangos de corte nos períodos inicial (0 a 10 dias), crescimento (11 a 24 dias) e final ( 25 a 35 dias). A suplementação de enzimas melhorou o ganho de peso corporal das aves no período inicial, e a conversão alimentar nos períodos de crescimento e final. Os autores indicaram o nível de 6\% para inclusão de DDGS nas dietas iniciais, e que pode ser aumentado para $12 \%$ nos períodos de crescimento e final sem prejudicar o desempenho, e a suplementação de enzimas em dietas que contenham DDGS pode melhorar a conversão alimentar de frangos de corte.

Ao fornecerem 6, 12 e 18\% de DDGS em dietas para frangos de corte, de um a 42 dias de vida, Lumpkins et al., (2005), verificaram que o ganho de peso e a conversão alimentar não foram afetados pela inclusão de DDGS até o nível de 12\%. Contudo, a inclusão de $18 \%$ de DDGS reduziu o ganho de peso e a conversão alimentar. Os autores atribuíram os resultados a uma provável deficiência de aminoácidos, uma vez que as dietas foram formuladas com base em aminoácidos totais e à baixa digestibilidade dos aminoácidos contidos no DDGS, especialmente o aminoácido lisina.

Ao avaliar o efeito da inclusão de 5\% de DDGS convencional (controle) e 10, 15 e 20\% de HP-DDGS na dieta de frangos de corte, no período de um a 42 dias de idade, Fries-Craft e Bobeck (2019), observaram que aves alimentadas com 15 e $20 \%$ de HP-DDGS apresentaram redução no ganho de peso de 4,9 e 4,2\%, respectivamente, quando comparado ao tratamento controle, além de promover piora na conversão alimentar de aves de 3,0 e 4,7\%. Esses autores observaram que dietas com maior inclusão de HP-DDGS resultaram em menor aporte de lisina e arginina, em comparação ao tratamento controle. Sendo assim, concluíram que inclusões de HP-DDGS que excedam a 10\% devem ser acompanhadas da correta suplementação de aminoácidos.

Wang et al., (2007) avaliaram a inclusão de cinco níveis (0 a 25\%) de DDGS na dieta de frangos de cortes, 
balanceadas para aminoácidos digestíveis, no período de um a 49 dias. Os níveis de DDGS não influenciaram o ganho de peso, contudo o consumo de ração e a conversão alimentar, no período de 1 a 35 dias e de 1 a 49 dias, foram maiores no nível de 25\% de inclusão de DDGS comparado ao tratamento controle. Um exame cuidadoso das concentrações totais de aminoácidos nas dietas sugeriu que as dietas com 25\% de DDGS apresentaram a arginina como aminoácido limitante, com relação arginina:lisina entre 102 a 104\%. A proporção ideal de lisina: arginina para frangos de corte é 105\% para aminoácidos totais e 107\% para aminoácidos digestíveis (Rostagno et al., 2017).

Efeitos deletérios do aumento da inclusão de HP-DDGS na dieta sobre o desempenho podem ser devido às diferenças no perfil aminoacídico. A formulação de dietas visando a substituição de ingredientes proteicos por coprodutos de alta proteína, com base apenas no teor de proteína bruta e energia metabolizável desses coprodutos, pode acarretar um teor aminoacídico superestimado (Fries-Craft \& Bobeck, 2019).

Aves jovens são mais sensíveis à qualidade dos ingredientes, uma vez que seu sistema digestivo não está totalmente desenvolvido, até os 14 dias de idade. Devido ao alto teor de fibras e a baixa digestibilidade de aminoácidos do DDGS, não se recomenda o fornecimento de dietas que contenham entre 25 a 30\% de DDGS, nas duas primeiras semanas de vida de frangos de corte (Batal \& Parsons, 2002). De fato, Wang et al. (2007), observaram que frangos de corte alimentados com dietas contendo 30\% de DDGS apresentaram menor peso corporal, aos 35 e 42 dias, em comparação as aves que receberam 0 ou $15 \%$ de DDGS. Porém, o peso corporal, aos 35 e 42 dias, das aves alimentadas com dietas com 0 ou 15\% de DDGS não diferiram entre si.

Oryschak et al., (2010) observaram que a suplementação de um complexo multi-enzimático (xilanase, glucanase, amilase, protease e invertase) é capaz de aumentar o valor nutritivo de DDGS de triticale para frangos de corte. Os autores observaram que a suplementação enzimática em dietas contendo 15\% de DDGS de triticale aumentou de 6 a 19\% a digestibilidade ileal de aminoácidos, bem como aumentou a digestibilidade ileal da proteína bruta e da energia bruta.

De acordo com Adeola et al., (2010), a digestibilidade ileal da energia do DDGS de milho, para frangos de corte, é de $2.340 \mathrm{kcal} / \mathrm{kg}$, a EMA é $2.315 \mathrm{kcal} / \mathrm{kg}$ e a EMAn é de $2.132 \mathrm{kcal} / \mathrm{kg}$. Os autores também observaram que a suplementação de xilanase e amilase melhorou e promoveu um aumento de $12 \%$ da digestibilidade ileal da energia, 5,7\% da EMA e 6,2\% da EMAn. Sugere-se que o nível de EMA de dietas que contém DDGS com alto teor de fibras pode superestimar a energia disponível para usos produtivos e resultar em maior produção de calor. Todavia, o emprego de enzimas em dietas de alta fibra pode proporcionar melhor utilização da energia da dieta.

Neste sentido, Barekatain et al. (2014), avaliaram o particionamento da energia em frangos de corte alimentados com dietas de baixa fibra (sem DDGS de sorgo) e alta fibra (30\% de DDGS de sorgo), com e sem inclusão da enzima xilanase. Os autores observaram que a inclusão de 30\% de DDGS na dieta afeta a partição energética, resultando em maior produção de calor e menor energia líquida, em comparação a dieta sem DDGS. A suplementação enzimática aumenta a energia retida, confirmando seu benefício, contudo não houve efeito sobre a eficiência da energia metabolizável e energia líquida.

A nutrição pode influenciar a pigmentação da carne, já que a presença de carotenoides, principalmente xantofilas, contribuem para aumento da intensidade amarela, característica desejada para pele, gema do ovo e tecido adiposo das aves (Perez-Vendrell et al., 2001). Sendo o DDGS de milho uma boa fonte de xantofila, maiores teores de vermelho (a*) 24h post mortem foram evidenciados na carne de frangos de corte alimentados com DDGS (10, 40, 70, 100, 130 e $160 \mathrm{~g} / \mathrm{kg}) \mathrm{em}$ comparação ao tratamento controle (Damasceno et al., 2020). Em estudo para avaliar a qualidade da carne de frangos de corte alimentados com DDGS $\left(0,5,10,15,20\right.$ e 25\%), Min et al. (2012) observaram maior intensidade de amarelo ( $\left.b^{*}\right)$ nos filés de peito das aves alimentadas com maiores níveis de DDGS. Esses resultados evidenciam a necessidade de padronização dos processos de produção de coprodutos de etanol, já que os carotenoides são extremamente susceptíveis a luz, oxigênio e temperatura, e podem ser danificados pelo calor excessivo durante a secagem (Salim et al., 2010). 
Os coprodutos da produção de etanol são fontes de energia e nutrientes para as aves e apresentam grande variações desses conteúdos entre os coprodutos, devendo-se tomar cuidado na formulação de dietas. Se for possível, os coprodutos devem ser de uma única fonte para minimizar as variações e análises químicas devem ser realizadas para verificar a composição química e estimar a biodisponibilidade de nutrientes (Bergendahl, 2008).

\section{Considerações Finais}

Essa revisão indica que os coprodutos da produção de etanol são uma fonte potencial de energia, proteína e fósforo para as aves. Entretanto, nutricionistas que utilizam esse alimento na dieta de aves devem estar cientes da variabilidade natural no teor de nutrientes e de sua digestibilidade, pois há muita diferença no processo fabril para a obtenção dos coprodutos, como por exemplo a remoção de fibras previamente à fermentação apresentam maior teor de proteína, tornando possível a inclusão de maiores quantidades nas dietas de aves, podendo este ser substituído integralmente ao farelo de soja.

Devido a essa grande variabilidade obtida no processo, é importante que pesquisas futuras sejam realizadas para se ter um padrão de obtenção de produtos, ou uma melhor caracterização desses coprodutos destinados a nutrição animal.

\section{Agradecimentos}

O presente trabalho foi realizado com apoio do Instituto de Ciências Agrárias e Ambientais, Campus Universitário de Sinop.

\section{Referências}

Abudabos, A. M., Al-Atiyat, R. M., Stanley, D., Aljassim, R., \& Albastshan, H. A. 2017. The effect of corn distiller's dried grains with solubles (DDGS) fortified with enzyme on growth performance of broiler. Environmental Science and Pollution Research. 24, 21412-21421. 10.1007/s11356-017-9808-5

Adeola, O., Jendza, J. A., Southern, L. L., Powell, S., \& Owusu-Asiedu, A. 2010. Contribution of exogenous dietary carbohydrase to the metabolizable energy value of corn distillers grains for broiler chickens. Poultry Science. 89(9), 1947-1954. 10.3382/ps.2010-00706

Alves, J. O., Zhuo, C., Levendis, Y. A., \& Tenório, J. A. S. 2012. Síntese de nanomateriais de carbono a partir do resíduo de milho (DDGS). Química Nova. 35(8), 1534-1537. 10.1590/S0100-40422012000800008

Associação Brasileira das Indústrias do Milho (2019). Oferta e demanda do milho - Brasil: ABIMILHO.

Associação Brasileira dos Produtores de Soja (2019). Acompanhamento da safra de soja: boletim nº 12/2019: APROSOJA.

Barekatain, M. R., Noblet, J., Wu, S. B., Iji, P. A., Choct, M., \& Swick, R. A. 2014. Effect of sorghum distillers dried grains with solubles and microbial enzymes on metabolizable and net energy values of broiler diets. Poultry Science. 93(11), 2793-2801. 10.3382/ps.2013-03766

Batal, A. B., \& Dale, N. M. 2006. True metabolizable energy and amino acid digestibility of distillers dried grains with solubles. Journal of Applied Poultry Research. 15: 89-93. 10.1093/japr/15.1.89

Batal, A. B., \& Parsons, C. M. (2002). Effect of age on development of digestive organs and performance of chicks fed a corn-soybean meal versus crystalline amino acid diet. Poultry Science. 81, 1338-1341. 10.1093/ps/81.9.1338

Borah, T. K., Kalita, N., Begum, K., sharma, P., \& Saikia, A. K. 2019. Effects of feeding different levels of distillers dried grains with solubles (DDGS) on performance of broiler chicken. International Journal of Chemical Studies. 7(6), 1230-1235. http://chemijournal.com

Bottger, C., \& Sudeum, K. H. 2017. Within plant variation of distillers dried grains with solubles (DDGS) produced from multiple raw materials in varying proportions: chemical composition and in vitro evaluation of feeding value for ruminants. Animal Feed Science and Technology. 229: 79-90. 10.1016/j.anifeedsci.2017.05.003

Bregendahl, K. (2008). Use of distillers co-products in diets fed to poultry. In Babcock, B.A.; Hayes, D.J.; Lawrence, J.D. (Eds.) Using distillers grains in the U.S. and international livestock and poultry industries (pp. 99-133). Ames: Iowa State University Digital Repository.

Cinelli, B. A., Castilho, L. R., Freire, D. M., \& Castro, A. M. 2015. A brief review on the emerging technology of ethanol production by cold hydrolysis of raw starch. Fuel. 150, 721-729. 10.1016/j.fuel.2015.02.063

Companhia Nacional de Abastecimento (2019). Acompanhamento da safra brasileira - Cana-de-açúcar. Brasília: CONAB.

Cooper, G., \& Weber, J. A. 2012. An outlook on word biofuel production and its implications for the animal feed industry. In: Makkar, H. P. S. Biofuel of coproducts as livestock feed: opportunities and challenges. Rome: FAO. 
Cozannet, P., Lessire, M., Gady, C., Métayer, J. P., Primo, Y., Skiba, F., \& Noblet, J. 2010. Energy value of wheat dried distillers grains with solubles in roosters, broilers, layers, and turkeys. Poultry Science. 89, 2230-2241. 10.3382/ps.2010-0083

Damasceno, J. L., Rocha, C. S., Eyng, C., Broch, J., Souza, C., Wachholz, L., Cirilo, E. H., Avila, A. S., Pires Filho, I. C., \& Nunes, R. V. (2020). Corn distillers' dried gains with solubles to feed broiler chickens from 22 to $42 \mathrm{~d}$ of age. Journal off Applied Poultry Research. 29, $273-583$. 10.1016/j.livsci.2020.104232

Eckert, C. T., Frigo, E. P., Albrecht, L. P., Albrecht, A. J. P., Christ, D., Santos, W. G., Berkembrock, E., \& Efewarth, V. A. (2018). Maize ethanol production in Brazil: characteristics and perspectives. Renewable and Sustainable Energy Reviews. 82, 3907-3912. 10.1016/j.rser.2017.10.082

El-Hack, M. E. A., Alagawany, M., Farag, M. R., \& Dhama, K. 2015. Use of maize distiller's dried grains with solubles (DDGS) in laying hen diets: trends and advances. Asian Journal of Animal and Veterinary Advances. 10(11), 690-707. 10.3923/ajava.2015.690.707

Fastinger, N. D., Latshaw, J. D., \& Maham, D. C. 2006. Amino acid availability and true metabolizable energy content of corn distillers dried grains with solubles in adult cecectomized roosters. Poultry Science. 85, 1212-1216. 10.1093/ps/85.7.1212

Foltyn, M., Rada, V., Lichovnikova, M., \& Dracková, E. (2013). Effect of corn DDGS on broilers performance and meat quality. Acta Universitatis Agriculturae et Silvicuturae Mendelianae Brunensis. 61, 59-64. 10.11118/actaun201361010059

Fontaine, J., Zimmer, U., Moughan, P. J., \& Rutherfurd, S. M. 2007. Effect of heat damage in an autoclave on the reactive lysine contents of soy products and corn distillers dried grains with solubles: use of the results to checks on lysine damage in common qualities of these ingredients. Journal of Agricultural and Food Chemistry. 55, 10737-10743.

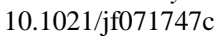

Fries-Craft, K., \& Bobeck, E. A. 2019. Evaluation of a high-protein DDGS product in broiler chickens: performance, nitrogen-corrected apparent metabolizable energy, and standardized ileal amino acid digestibility. British Poultry Science. 60(6), 749-756. 10.1080/00071668.2019.1652884

Gouveia, A. B. V. S., Paulo, L. M., Silva, J. M. S., Sousa, F. E., Almeida Junior, E. M., Costa, \& Minafra, C. S. (2020). Alimentos alternativos utilizados para codornas de corte: revisão. Research, Society and Development. 9(2), e172922250. 10.33448/rsd-v9i2.2250

Hoffman, L., \& Baker, A. Market issues and prospects for U.S. distillers' grains: supply, use, and price relationships: USDA, 2010.

Hussain, M., Mirza, M. A., Nawaz, H., Asghar, M., \& Ahmed, G. (2019). Effect of exogenous protease, mannase, and xylanase supplementation in corn and high protein corn DDGS based diets on growth performance, intestinal morphology and nutrient digestibility in broiler chickens. Brazilian Journal of Poultry Science. 21(4), 001-010. 10.1590/1806-9061-2019-1088

Jacela, J. Y., Frobose, H. L., DeRouchey, J. M., Tokach, M. D., Dritz, S. S., Goodband, R. D., \& Nelssen, J. L. 2010. Amino acid digestibility and energy concentration of high-protein corn dried distillers grains and high-protein sorghum dried distillers grains with solubles for swine. Journal of Animal Science. 88, 3617-3623. 10.2527/jas.2010-3098

Jung, B., \& Batal, A. B. (2010). Evaluation of high protein distillers' dried grains as a feed ingredient for broiler chickens. Canadian Journal of Animal Science. 90(4), 505-512. doi:10.4141/cjas 10030

Kelsall, D. R., \& Lyons, T. P. (1999) Grain dry milling and cooking for alcohol production: designing for 23 percent ethanol and maximum yield. In: The alcohol textbook. (3rd Ed.) Jacques, K. A., Lyons, T. P., \& Kelsall, D. R. Nottingham, UK.: Notthingham University Press.

Kim, E. J., Martinez-Amezcua, C., Utterback, P. L., \& Parsons, C. M. 2008. Phosphorus bioavailability, true metabolizable energy and amino acid digestibilities of high protein corn distillers dried grains and dehydrated corn germ. Poultry Science. 87, 700-705. 10.3382/ps.2007-003

Kim, S., \& Dale, B. E. 2009. Regional variations in greenhouse gas emissions of biobased products in the United States corn based ethanol and soybean oil. The International Journal of Life Cycle Assessment. 14, 540-546. 10.1007/s11367-009-0106-4

Klasing, K. C., \& Austic, R. E. 2003. Nutritional disease. In: SAIF, Y. M. Diseases of poultry. (pp. 1027-1053). (11a Ed.): Iowa State Press.

Kleinschmit, D. H., Anderson, J. L., Schingoethe, D. J., Kalscheur, K. F., \& Hippen, A. R. (2007). Ruminal and intestinal degradability of distillers grains plus solubles varies by source. Journal of Dairy Science. 90, 2909-2918. 10.3168/jds.2006-613

Leeson, S., \& Summers, J. D. (2005). Commercial poultry nutrition. (3rd ed.) Guelph, ON: Nottingham University Books.

Liu, K. (2011). Chemical composition of distillers grain, a review. Journal of Agricultural and Food Chemistry. 59, 1508-1526. 10.1021/jf103512z

Loy, D. D., \& Lundy, E. L. (2019). Nutritional properties and feeding value of corn and its coproducts. In: SERNA-SALDIVAR, S. O. Corn: chemistry and thechnology (pp. 633-659). (3rd Ed.) St. Paul: AACC.

Lumpkins, B. S., Batal, A., \& Dale, N. (2005). Use of distillers dried grains plus solubles in laying hen diets. Journal of Applied Poultry Research. 14, 25-31. 10.1093/japr/14.1.25

Martinez-Amezcua, C., Parsons, C. M., Singh, V., Srinivasan, R., \& Murthy, G. S. 2007. Nutritional characteristics of corn distillers dried grains with solubles as affected by the amounts of grain versus solubles and different processing techniques. Poultry Science. 86, 2624-2630. 10.3382/ps.2007-00137

Mauron, J. 1990. Influence of processing on protein quality. Journal of Nutritional Science and Vitaminology. 36, S57-S69. 10.3177/jnsv.36.4Supplementi_s57

Mim, Y. N., Li, L. L., Liu, S. K., Zhang, J., Gao, Y. P., \& Liu, F. Z. (2015). Effects of dietary distillers dried grains with solubles (DDGS) on growth performance, oxidative stress and immune function in broiler chickens. Journal of Applied Poultry Research. 24, 23-29. 10.3382/japr/pfv002 
Min, Y. N., Li, L., Waldroup, P. W., Niu, Z. Y., Wang, Z. P., Gao, Y. P., \& Liu, F. Z. (2012). Effects of dietary distillers dried grains with solubles concentrations on meat quality and antioxidant status and capacity of broiler chickens. Journal of Applied Poultry Research. 21, 603-611. 10.3382/japr.201100503

Monceaux, D. A., \& Kuehner, D. (2009). Dryhouse technologies and DDGS production. In: Ingledew, W.M.; Kelsall, D.R.; Austin, G.E. The alcohol textbook (pp. 303-322). (5th ed.): Nottingham University Press.

Noblet, J., Cozannet, P., \& Skiba, F. 2012. Nutritional value and utilization of wheat dried distillers grain with solubles in pigs and poultry. In: Makkar, H. P. S. Biofule of co-products as livestock feed: opportunities and challenges: FAO.

Oliveira, R. L., Leão, A. G., Abreu, L. L., Teixeira, S., \& Silva, T. M. 2013. Alimentos alternativos na dieta de ruminantes. Revista Científica de Produção Animal. 15(2), 141-160. 10.15528/2176-4158/rcpa.v15n2p141-160

Oryschak, M., Korver, D., Zuidhof, M., \& Beltranena, E. (2010). Nutritive value of single-screw extruded and nonextruded triticale distillers dried grains with solubles, with and without an enzyme complex, for broilers. Poultry Science. 89(7), 1411-1423. 10.3382/ps.2009-00619

Osho, S. O., Babatunde, O. O., \& Adeola, O. (2019). Additivity of apparent and standardized ileal digestibility of amino acids in wheat, canola meal, and sorghum distillers dried grains with solubles in mixed diets fed to broiler chickens. Poultry Science. 98, 1333-1340. 10.3382/ps/pey457

Pedersen, M. B., Dalsgaard, S., Knudsen, K. E. B., \& Laerke, H. N. 2014. Compositional profile and variation of distillers dried grains with solubles from various origins with focus on non-starch polysaccharides. Animal Feed Science and Technology. 197, 130-141. 10.1016/j.anifeedsci.2014.07.011

Pereira, A. S., Shitsuka, D. M., Parreira, F. J., \& Shitsuka, R. (2018). Metodologia da pesquisa científica. [e-book]. Santa Maria. Ed. UAB/NTE/UFSM. https://repositorio.ufsm.br/bitstream/handle/1/15824/Lic_Computacao_Metodologia-Pesquisa-Cientifica.pdf?sequence=1.

Perez-Vendrell, A. M., Hernandez, J. M., Llaurado, L., Schierle, J., \& Brufau, J. (2001). Influence of source and ratio of xanthophyll pigments on broiler chicken pigmentation and performance. Poultry Science. 80, 320-326. 10.1093/ps/80.3.320

Rausch, K. D., \& Eckhoff, S. R. 2016. Maize: wet milling. Encyclopedia of Food Grains. 3, 467-481. 10.1016/B978-0-12-394437-5.00239-4

Rausch, K. D., Hummel, D., Johnson, L. A., \& May, J. B. 2019. Wet milling: the basics for corn biorefineries. In: Serna-Saldivar, S. O. Corn: chemistry and thechnology (pp. 501-535). (3rd. Ed.): AACC.

Renewable Fuels Association (2020). Focus forward: 2020 ethanol industry outlook. Ellisville: RFA.

Roper, J. M., Smith, B. L., Rae, J. M. C., Huang, E., Walker, C. A., McNaughton, J. L., Chen, A., \& Reidinger, K. S. 2019. Nutrient composition and safety evaluation of simulated isobutanol distillers dried grains with solubles and associated fermentation metabolites when fed to male Ross 708 broiler chickens (Gallus domesticus). PLOS One. 14(7), 1-25. 10.1371/journal.pone.0219016

Rostagno, H. S., Albino, L. F. T., Hannas, M. I., Donzele, J. L., Sakomura, N. K., Perazzo, F. G., \& Brito, C. O. 2017. Tabelas brasileiras para aves e suínos: composição de alimentos e exigências nutricionais: UFV.

Salim, H. M., Kruk, Z. A., \& Lee, B. D. (2010). Nutritive value of corn distillers dried grains with soluble as an ingredient of poultry diets: a review. World's Poultry Science Journal. 66, 411-432. 10.1017/S0043933910000504

Schöne, R. A., Nunes, R. V., Frank, R., Eyng, C., Castilha, L. D., Schöne, R. A., \& Castilha, L. D. 2017. Resíduo seco de destilaria com solúveis (DDGS) na alimentação de frangos de corte (22-42 dias). Revista Ciência Agronômica, 48(3), 548-557. 10.5935/1806-6690.20170064

Shim, M. Y., Pesti, G. M., Bakalli, R. I., Tillman, P. B., \& Payne, R. L. (2011). Evaluation of DDGS as an Alternative Ingredient for Broiler Chickens. Poultry Science. 90, 369-376. 10.3382/ps.2010-00727

Shurson, J., \& Alghamdi, A. S. (2008). Quality and new technologies to create corn co-products from ethanol production. In: Babcock, B., Hayes, D. J., Lawrence, J. D. Using distillers grains in the U.S. and international livestock and poultry industries (pp. 231-259). MATRIC: Iowa State University.

Spiehs, M. J., Whitney, M. H., \& Shurson, G. C. (2002). Nutrient database for distiller's dried grains with solubles produced from new ethanol plants in Minnesota and South Dakota. Journal of Animal Science. 80, 2639-2645. 10.2527/2002.80102639x.

Srinivasan, R., To, F., \& Columbus, E. (2009). Pilot scale fiber separation from distillers dried grains with solubles (DDGS) using sieving and air classification. Bioresource Technology. 100, 3548-3555. 10.1016/j.biortech.2009.02.049

Stein, H. H. (2008). Use of distillers co-products in diets fed to swine. In: Babcock, B.A.; Hayes, D.J. \& Lawrence, J. D. Using distillers grains in the U.S. and international livestock and poultry industries (pp. 79-97): Iowa State University Digital Repository.

Stein, H. H., Gibson, M. L., Pedersen, C., \& Boersma, M. G. (2006). Amino acid and energy digestibility in ten samples of distillers dried grain with solubles fed to growing pigs. Journal of Animal Science. 84, 853-860. 10.2527/2006.844853x

Stein, H. H., \& Shurson, G. C. 2009. Board-invited review: the use and application of distillers dried grains with solubles in swine diets. Journal of Animal Science. 87(4), 1292-1303. 10.2527/jas.2008-1290

Vosgerau, D. S. R., \& Romanowski, J. P. (2014) Estudos de revisão: implicações conceituais e metodológicas. Revista Diálogo Educacional. 14(41), 165-189. 10.7213/dialogo.educ.14.041.DS08

Wang, Z., Cerrate, S., Coto, C., Yan, F., \& Waldroup, P. W. (2007). Use of constant or increasing levels of distillers dried grains with solubles (DDGS) in broiler diets. International Journal of Poultry Science. 6(7), 501-507. 10.3923/ijps.2007.501.507

Wyman, C. E. (1996). Handbook on bioethanol: production and utilization: Taylor \& Francis, 1996. 